\title{
Peculiarities of Autonomic Regulation of Heart Rate in Athletes with Different Age
}

\begin{abstract}
The aim of the work is study of peculiarities of autonomic regulation of heart rate in athletes with different age. Three groups of elite athletes (members of Ukraine National Team of Greco-Roman wrestling) were examined. The first group - 15 athletes, aged 19-21, the second group -.14 athletes, aged 22-25 and the third group - 12 athletes, aged over 25 . The statistical method of analysis for estimation of states of autonomic regulation of heart rate was used. The athletes of older age group have bigger level of tension of autonomic regulation comparing to younger athletes was revealed. This is confirmed by low values of STD RR and RR triangular index. The spectral analysis of cardiointervals show of more consummate system of autonomic regulation in athletes of third age group. But the age changes influence to activation of compensatory mechanisms of prevention of involution process. The grown of level of tension of regulation of heart rate in athletes of older age group connective with slowdown of periodic and aperiodic oscillation.
\end{abstract}

Short Communication

Volume 11 Issue 1 - 2018

Korobeynikov G*, Korobeynikova L, Mischenko V and Pastikhova V

National University of Physical Education and Sport, Ukraine

*Corresponding author: Georgiy Korobeynikov, National University of Physical Education and Sport, Kiev, Ukraine, Email: george.65@mail.ru

Received: August 30, 2016 | Published: February 20, 2018

\section{Introduction}

The system of autonomic regulation of heart rate is a key components of functional states of organism of athletes in tension muscular activity condition [1-3]. There are more approaches for estimation of character of reaction of system of regulation of cardio intervals on the physical load. But, in really condition the conducting of control for functional states of athletes the most common is the use of portable cardiomonitor [4-6].

The differentiation of age during training process in elite athletes as factor sport longevity is a main problem for modern Olympic sport $[7,8]$. This is conditioned by bigger of elite athletes who has high level of sport achievements in 30 and over age [9].

Many works devoted by elaboration of training programs for elite athletes of different age. But not sufficient studies which dedicated of peculiarities of autonomic regulation of heart rate in elite athletes with different age.

The aim of the work is study of peculiarities of autonomic regulation of heart rate in athletes with different age.

\section{Methods}

Three groups of elite athletes (members of Ukraine National Team of Greco-Roman wrestling) were examined. The first group
- 15 athletes, aged 19-21, the second group -.14 athletes, aged 22-25 and the third group - 12 athletes, aged over 25. From all of the athletes before the study was gave permission on used the results of the study for scientific purposes. From of athletes written authorization has been received in accordance with to recommendation of ethical committees.

The statistical method of analysis for estimation of states of autonomic regulation of heart rate was used. Were used the cardio monitor «Polar RS800CX» [10]. The received results were indicates in protocol of statistically programs «KubiosHRV».

\section{Results}

The average values of autonomic regulation of heart rate in athletes of different age are presented in Table 1. The analysis showed of differences between all groups of athletes. In third age group of athletes observed of more level of heart rate (Mean RR and Mean HR) for younger athletes (Table 1). The declines level of values of STD RR and RR triangular index in athletes of third age group for concerning younger athletes indicates of increasing of tension of heart rate regulation system (Table 1). Thus, the increasing level of tension of regulation of heart rate in athletes of older age group for concerning to younger athletes was established. This fact displays in acceleration of heart rate in athletes of third age group.

Table 1: Values of autonomic regulation of heart rate in athletes of different age groups $(X \pm S(X), n=41)$.

\begin{tabular}{|c|c|c|c|}
\hline \multirow{2}{*}{ Values } & \multicolumn{3}{|c|}{ Age Groups } \\
\cline { 2 - 4 } & First (n=15) & Second $(\mathbf{n = 1 4})$ & Third (n=12) \\
\hline Mean RR, ms & $1114,96+49,80$ & $1080,11+34,50$ & $986,10+33,01^{* * *}$ \\
\hline STD RR, ms & $125,21+4,37$ & $112,33+3,71^{*}$ & $101,28+2,99^{* * *}$ \\
\hline Mean HR, 1/min & $55,17+2,30$ & $56,71+1,59$ & $63,29+3,52^{* * *}$ \\
\hline RR triangular index & $19,81+0,86$ & $20,09+1,18$ & $13,92+1,83^{* * *}$ \\
\hline
\end{tabular}

Notes:

$1 .^{*}$-p $<0,05$, concerning to first group;

2 . $^{* *}-\mathrm{p}<0,05$, concerning to second group. 
The data of spectral characteristics of variability of heart rate in athletes of different age are show in Table 2. The analysis of this data indicates about significant differences between all of the age groups of athletes on spectral values.

The high level of activity of VLF spectrum is observed in athletes of third group, the low level - in athletes of first and second age groups (Table 2). This circumstance indicates the intensification of activity of neurohumoral centers of autonomic nervous system of athletes in age involution condition during adaptation to muscular load $[11,12]$. At the same time the values of LF oscillation spectrum of heart rhythm in athletes of third age group low than concerning to young athletes (Table 2). This fact indicates of optimal activation of sympathetic part of autonomic nervous system in athletes of third age group.

Table 2: Values of spectral characteristics of heart rate variability in athletes of different age groups $(X \pm S(X), n=41)$.

\begin{tabular}{|c|c|c|c|}
\hline \multirow{2}{*}{ Values } & \multicolumn{3}{|c|}{ Age Groups } \\
\cline { 2 - 4 } & First (n=15) & Second (n=14) & Third (n=12) \\
\hline VLF, ms2 & $9501,86+382,01$ & $7392,82+254,19^{*}$ & $10105,20+581,64^{* *}$ \\
\hline LF, ms2 & $3164,43+359,55$ & $2849,82+266,26$ & $2260,10+310,51^{*}$ \\
\hline HF, ms2 & $2807,00+231,49$ & $2471,82+197,38$ & $13928,30+2428,02^{* * *}$ \\
\hline LF/HF & $1,48+0,03$ & $1,64+0,01$ & $1,94+0,06^{*}$ \\
\hline
\end{tabular}

Notes:

$1 .^{*}$-p $<0,05$, concerning to first group;

$2 .^{* *}$-p $<0,05$, concerning to second group.

Similar results received for values of HF oscillation spectrum of cardiointervals (Table 2). The results show of high activation of parasympathetic tone of autonomic regulation of heart rhythm in athletes of older age group for comparing to younger age group athletes.

But values of ratio LF/HF is consistent with results of STD RR (Table 1). The result obtained indicates of increase of stresses of regulation of heart rate during increasing of age of athletes. Thus, the spectral analysis of cardiointervals find out of perfective system of autonomic regulation in athletes of third age group. But the age changes influence to activation of compensatory mechanisms of prevention of involution process. This consistent with the strengthening of activity of neurohumoral centers and parasympathetic link of autonomic nervous system with the simultaneous of growth of level of stresses of heart rate regulation.

Which is in the law of the LORD, which he made with the tabernacle of the congregation, which he made with the tabernacle of the congregation. The absolute values of skaterogramm of heart rate variability (Poincare plot) in athletes of different age groups is presented on Table 3 . The results show about availability of reliable changes between athletes of different age groups for two parameters of skaterogramm (Table 3). The decline of meanings of SD1 in athletes of older age group comparing to younger athletes are demonstrates to slowdown of aperiodic oscillation of heart rhythm. Lower values of SD2 in older athletes comparing to younger athletes indicate about slowdown of periodic oscillation of heart rhythm (Table 3). It is consistent to data of spectral analysis of heart rhythm (Table 2).

Table 3: Values of skaterogramm of heart rate variability (Poincare plot) in athletes of different age groups $(X \pm S(X), n=41)$.

\begin{tabular}{|c|c|c|c|}
\hline \multirow{2}{*}{ Values } & \multicolumn{3}{|c|}{ Age Groups } \\
\cline { 2 - 4 } & First (n=15) & Second (n=14) & Third (n=12) \\
\hline SD1, ms & $67,71+5,41$ & $62,26+7,79$ & $47,68+6,33^{* * *}$ \\
\hline SD2, ms & $160,37+10,22$ & $142,95+15,16^{*}$ & $132,69+18,99^{* * *}$ \\
\hline
\end{tabular}

Notes:

$1{ }^{*}$-p $<0,05$, concerning to first group;

$2 .^{* *}$-p $<0,05$, concerning to second group.

Thus, increasing of level of tension of regulation of heart rate in athletes of older age group is accompanied by slowdown of periodic and aperiodic oscillation.

\section{Discussion}

Summing conclusion can be noted that athletes of older age group have bigger level of stresses of heart rhythm regulation for concerning to younger athletes. This related with the beginning of process of age involution in organism of older athletes. Simultaneously with the growth of tension of regulation of heart rate in athletes of older age group show of activation of neurohumoral centers and active of parasympathetic link of autonomic nervous system. This mechanism indicates on ways of destraction in regulation systems of organism of athletes of third age group. 
The growth of level of growth of tension of regulation of heart rate in athletes of older age group accompanied by slowdown of periodic and aperiodic oscillation. Observed results is bound of peculiarities of age changes of autonomic regulation in athletes in muscular activity condition.

\section{Conclusion}

1. The athletes of older age group have bigger level of tension of autonomic regulation comparing to younger athletes was revealed. This is confirmed by low values of STD RR and RR triangular index.

2. The spectral analysis of cardiointervals show of more consummate system of autonomic regulation in athletes of third age group. But the age changes influence to activation of compensatory mechanisms of prevention of involution process.

3. The grown of level of tension of regulation of heart rate in athletes of older age group connective with slowdown of periodic and aperiodic oscillation.

\section{References}

1. Baevsky RM (2004) Analysis of heart rate variability: history and philosophy, theory and practice. Clinical Informatics and Telemedicine 1: 54-64.

2. Kovalenko SO (2005) Analysis of variability of heart rhythm for support of method of median spectrograms. Fiziologichniy Jornal 51: $92-95$

3. Nowosielska-Swadźba D, Zwolińska D, Jendrysek M, Podstawski R (2015) Physical activity as a health factor modifying heart rate variability (HRV). Pedagogics, psychology, medical-biological problems of physical training and sports $3: 80-86$
4. Aubert AE, Steps B, Becker F (2003) Heart rate variability in athletes. Sports Med 33(12): 889-919.

5. Tulppo M P, Haghson RL, Makikallio TH, Airaksinen KE, Seppänen $\mathrm{T}$, et al. (2001) Effect of exersice and passive head-up tilt on fractal and complexity properties of heart rate dynamics. Am J Physiol Heart Circ Physiol 280(3): 1082-1087.

6. Korobeynikov G, Korobeinikova L, Iermakov S, Nosko M (2016) Reaction of heart rate regulation to extreme sport activity in elite athletes. Journal of Physical Education and Sport 16: 976-981.

7. Kozina Z, Sobko I, Bazulyuk T, Ryepko O, Lachno O, et al. (2015) The applying of the concept of individualization in sport. Journal of Physical Education and Sport 15(2): 172-177.

8. Platonov VN (2013) Periodization of sports training. Basic theory and its practical approach: 624 .

9. Platonov VN, Pavlenko IA, TomashevskijVV (2012) Preparation of national teams to Olympic Games: 310 .

10. Korobeynikov G, Korobeynikova L, Chernozub A, Makarchuk M (2013) The Autonomic Regulation of Heart Rate of Athletes with Different Levels of Sensor Motor Response 4: 262.

11. Lucini D, Vigo F, Tosi G, Toninelli F, Badilini M, et al. (2014) Assessing autonomic response to repeated bouts of exercise below and above respiratory threshold: insight from dynamic analysis of RR variability. Eur J Appl Physiol 114(6): 1269-1279.

12. Recordati G (2003) A thermodynamic model of the sympathetic and parasympathetic nervous systems. Auton neurosci 103(1-2): 1-12. 